\title{
Quntative Expression of Cell Death by LDH Activity
}

\author{
Nahum Rosenberg ${ }^{1}$, Kamal Hamoud ${ }^{1}$, Orit Rosenberg ${ }^{2}$ \\ ${ }^{\prime}$ Orthopaedics Department, Rambam Health Care Campus and Ruth and Bruce Rappaport Faculty of Medicine, \\ Technion - Israel Institute of Technology, Haifa, Israel \\ ${ }^{2}$ Sheltagen Medical Ltd, Atlit, Israel
}

\begin{abstract}
We hypothesize that a universal quantitative relation exists between the number of necrotic cells in culture and LDH activity in culture media. Previously this relation was found in immortalised cell lines. We hypothesized that similar correlation exists in normal cells of human origin. We investigated cultured human oseoblast-like cells. LDH activity in the media of cultured samples $(n=8)$ was determined by $340 \mathrm{~nm}$ wavelength spectrophotometry. Cell viability was determined using automated cell counter. Significant and high correlation was found between LDH activity in culture media and the numbers of non-viable cells ( $n=8, C C-0.95$, power0.984, SE $=13,920, p<0.001$ ). These findings support the use of media LDH activity measurements for estimation of cell death rate in culture without the need of a major manipulation of the cultured cells.
\end{abstract}

Keywords: LDH, cell death, osteoblast, cell viability, cell number.

\section{Introduction}

The number of cells in in vitro culture is determined by the rate of cell proliferation and the rate of cell death. These parameters are usually measured in order to characterize a specific cell culture. The main obstacle in determining these parameters is the necessity to interfere with culture progress when manipulation of cells is required in different tests. In the case of the determination of cell death rate a "minimally invasive" method of measurement of LDH activity in culture media was suggested and established (Legrand et al. 1992). The rationale for this method originates from the fact that the intracellular enzyme lactate dehydrogenase (LDH) leaks out of the cells through damaged cell membrane of non-viable cells when the cell death progresses. Therefore, the measurement of LDH activity in culture media reflects the cell necrosis level of the cultures cells. Usually in order to quantify the rate of cell necrosis under specific conditions a comparison to control cultures exposed only to the vehicle of the tested culture conditions is utilized (Rosenberg et al. 2011; Rosenberg et al. 2013; Rosenberg et al. 2014). Much easier approach would be if a direct quantification of necrotic cells from the culture LDH activity would be possible. Although the initial report of this method presented a linear dependence between the number of necrotic cells in culture and the LDH activity in the culture media of BHK21/C13 cells (Legrand et al. 1992), that report has not been repeated yet on the same cells' type or in other type of cells and therefore it is not apparent if an universal quantitative relation between the number of necrotic cells in culture and the LDH activity level in the culture media exists. Such knowledge might promote the ability to study the cell culture behavior without the necessity of major manipulation of the cultured cells.

In order further promote the use of the method of cell necrosis measurement we investigated the quantitative relation between cellular necrosis and LDH activity in culture media in different from the previously studied cell type (Legrand et al. 1992). i.e. we investigated cultures of human osteoblast-like cells, which are highly metabolically active mature cells. We hypothesized that a similar quantitative to the previously published relation between the studied parameters might be found in these cells. Such finding should indicate on a constant relation of these parameters in different cell types and will allow further confident use of measurement of LDH activity in culture media that should reflect a specific number of necrotic cells in a specific cell culture conditions.

\section{Methods}

This experimental protocol was approved by the institutional Ethical Committee.

\section{Cell Culture}

In this study we used oseoblast-like cells of human origin originated from cancellous bone from distal femur. The cancellous bone samples were taken from the disposable bone tissue during osteoarthritic knee arthroplasty. Chips of cancellous bone, $2-3$ grams in total, were incubated in DMEM with heat-inactivated fetal calf serum $(10 \%), 20 \mathrm{mM}$ HEPES buffer, $2 \mathrm{mM}$ L-glutamine, $100 \mu \mathrm{M}$ ascorbate-2-phosphate, 10nM dexametasone, $50 \mathrm{U} \mathrm{ml}-\mathrm{ml}$ penicillin, $150 \mu \mathrm{ml}-\mathrm{ml}$ streptomicin at $37^{\circ} \mathrm{C}$ in humidified atmospheric environment of $95 \%$ air with $5 \% \mathrm{CO}_{2}$ (v:v ) for 20 days. Human osteoblast-like cells grew out from the chips as adherent to the plastic culture plates until confluence. The human bone cell cultures obtained by this method have been shown previously to express osteoblast-like characteristics (Gundle et al. 1998, Rosenberg et al. 2010). These 
cells were passaged into 8 wells in plastic 24 well plate. Each well was seeded with equal number of cells $\left(10^{4}\right.$ cells) and cultured for 6 days in the above described osteogenic media with starting LDH activity in culture media of $15.5 \mathrm{U} / \mathrm{L}$. On the $7^{\text {th }}$ day of culture the media from all samples was collected for the LDH assay and the necrotic cells were counted by cytometric analysis.

\section{LDH Activity in Culture Media}

LDH activity in media of cultured samples was determined by $340 \mathrm{~nm}$ wavelength spectrophotometry of reduced nicotineamide adenine dinucleotide (NAD), which is directly proportional to LDH activity (Gay and Bowers 1968), i.e. measurement of oxidation of $\mathrm{L}$ - lactate to pyruvate at $\mathrm{pH}=8.55$ in Tris buffer $15.3 \mu \mathrm{mol} / \mathrm{L}$ (Gay and Bowers 1968). The range of the assay was 0-600 U/l (spectrophotometer - Dimension AR IMT 110V/60HZ, Dade Behring, Inc. Newark, DE).

From the measured total LDH activity in all samples the basic activity of the LDH in the original media before its addition to cells was deduced, i.e. deduction of $15 \mathrm{U} / \mathrm{l}$ value from the final measurements of LDH activity, in order to measure the "true" LDH leak from damaged cells.

\section{Cell number and Viability by Automatic Cytometry}

Cell number and cell viability was determined using automated cell counter $\left(1450101 \mathrm{TC} 20^{\mathrm{TM}}\right.$, BioRad laboratories Inc. Hercules, CA, USA) . Prior to counting the cells were re-suspended in $0.4 \%$ Trypan blue solution in order to distinguish between viable and non-viable cells (non-viable cells have permeable membranes and therefore stained by to Trypan blue).

\section{Statistical Analysis}

The number of non-viable cells and the LDH activity in media were correlated by Pearson Product Moment correlation (Bourke et al. 1985). (Bourke et al. 1985). We used SigmaPlot 12.5 software (Systat Inc, USA) for the statistical calculations.

\section{Results}

Significant and high correlation was found between LDH activity in culture media and the numbers of non-viable cells $(n=8$, correlation coefficient -0.95 , power $-0.984, S E=13,920, p<0.001$, Pearson Product Moment Correlation, Fig. 1). This correlation shows that LDH activity of $10 \mathrm{U} / \mathrm{L}$ represents $28,677 \pm 13,920$ non-viable cells, i.e. between 15,000 - 42,597 non-viable cells.

\section{Discussion}

Our results show similar to the previously reported correlation between the number of of the necrotic cells and LDH activity in culture media (1). Since we investigated normal human cells and reached similar quantitave results to the original report where malignant cell lines were investigated we can cautiously conclude on the relatively universal relation between the quantity of necrotic cells in culture and LDH activity in culture media. We think that this indication is of important practical use because it enables estimation of cell death rate in culture without the need of major manipulation of cultured cells.

Figure 1:

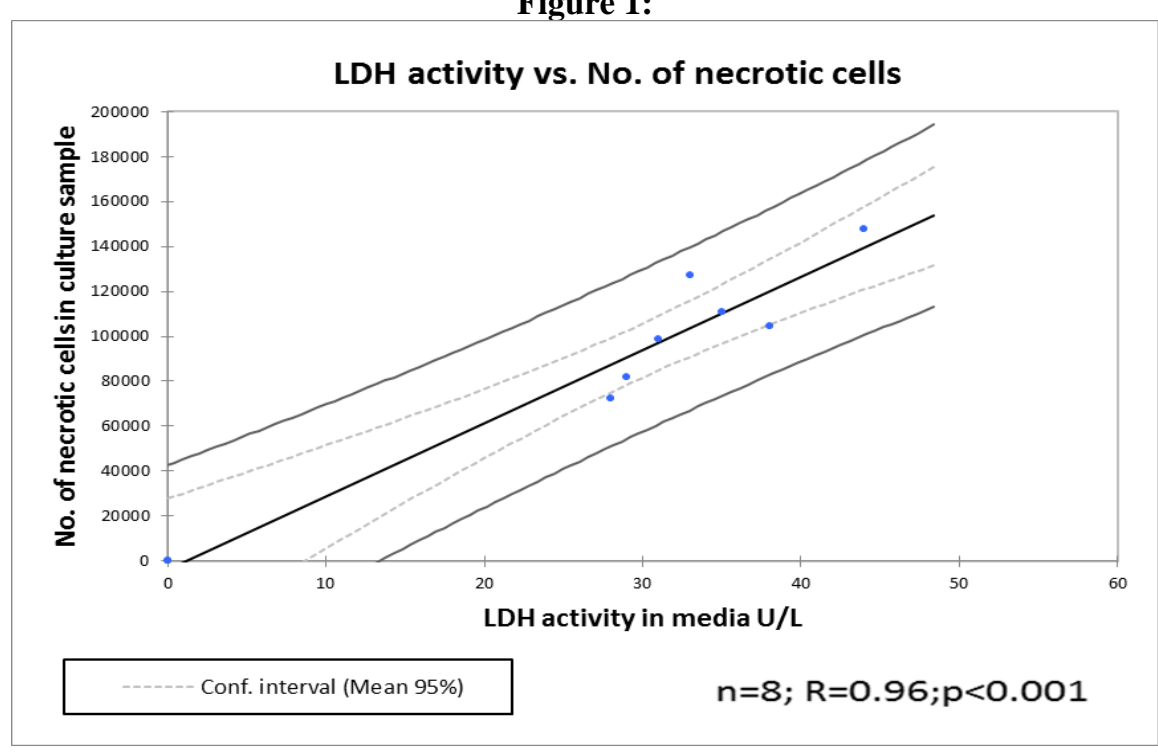




\section{References}

[1]. Bourke GJ, Daly LE, McGilvray (ed) (1985) Interpretation and Uses of Medical Statistics. Third Edition, Blackwell Scientific Publication, Oxford, London, pp.131-152.

[2]. Gay RB, Bowers GN Jr (1968) Optimum reaction conditions for human lactate dehydrogenase isoenzymes as they affect total lactate dehydrogenase activity. Clin Chem. 14(8):740-53.

[3]. Gundle R, Stewart K, Screen J, Beresford J.N (1998) Isolation and culture of human bone-derived cells. In: Marrow stromal cell culture. Beresford N \& Owen ME (ed) Cambridge university press, Cambridge, UK, pp 43-66

[4]. Legrand, C., Bour, J.M., Jacob, C., Capiaumont, J., Martial, A., Marc, A., Wudtke, M., Kretzmer, G., Demangel, C., Duval, D. Hache, J. (1992) Lactate dehydrogenase (LDH) activity of the number of dead cells in the medium of cultured eukaryotic cells as marker. J Biotechnol 25,231-243.

[5]. Rosenberg N, Rosenberg O, Weizman A' Leschiner S, Sakoury J, Fares F, Soudry M, Weisinger G, Veenman L, Gavish M (2011) In vitro mitochondrial effects of PK 11195, a synthetic translocator protein $18 \mathrm{kDa}$ (TSPO) ligand in human osteoblast-like cells. J Bioenerg Biomembr 43: 739-746

[6]. Rosenberg N, Rosenberg O, Weizman A, Veenman L, Gavish M (2013) In vitro catabolic effect of protoporphyrin IX in human osteoblast-like cells: possible role of the $18 \mathrm{kDa}$ mitochondrial translocator protein. J Bioenerg Biomembr 45:333-341

[7]. Rosenberg N, Rosenberg O, Weizman A, Veenman L, Gavish M (2014) In Vitro effect of FGIN-1-27, a Ligand to 18 kDa Mitochondrial Translocator Protein, in Human Osteoblast-like Cells . J Bioenerg Biomembr 46:197-204.

[8]. Rosenberg N, Soudry M, Rosenberg O, Blumenfeld I, Blumenfeld Z (2010) The role of activin A in the human osteoblast cell cycle: a preliminary experimental in vitro study. Exp Clin Endocrinol Diabetes 118:708-712. 